\title{
Analisis Kebutuhan Pengembangan Multimedia Interaktif Berbasis Problem Based Learning pada Materi Biologi SMA
}

\author{
Rinu Bhakti Dewantara ${ }^{1}$, Endang Suarsini ${ }^{1}$, Sri Rahayu Lestari ${ }^{1}$ \\ ${ }^{1}$ Pendidikan Biologi-Universitas Negeri Malang
}

\section{INFO ARTIKEL}

\section{Riwayat Artikel:}

Diterima: 18-07-2019

Disetujui: 17-06-2020

\section{Kata kunci:}

interactive multimedia; problem based learning; biology;

multimedia interaktif; problem based learning; biologi

\begin{abstract}
ABSTRAK
Abstract: The aim of research was to analyze the need for multimedia based on Problem Based Learning in biological matter. This research is a qualitative descriptive study. The method used is in the form of a questionnaire (questionnaire). Questionnaires were given to 67 students of SMAN 1 Way Jepara in August 2017. The data were analyzed using descriptive analysis. The results indicates that $67.2 \%$ of students stated that the material immune system was considered the most difficult, $93.3 \%$ of students wanted the development of new learning media, $54 \%$ of students wanted interactive multimedia. The conclusion of this study is that it is necessary to develop learning media in the form of interactive multimedia based on Problem Based Learning in for XI classs students Immune System material.
\end{abstract}

\begin{abstract}
Abstrak: Tujuan penelitian ini adalah untuk menganalisis kebutuhan terhadap multimedia interaktif berbasis Problem Based Learning pada materi Biologi. Penelitian ini merupakan penelitian deskriptif kualitatif. Metode yang digunakan berupa angket (kuesioner). Angket diberikan kepada 67 siswa SMAN 1 Way Jepara Agustus 2017. Data dianalisis menggunakan analisis deskriptif. Hasil penelitian ini menunjukkan bahwa $67,2 \%$ siswa menyatakan bahwa materi sistem imun merupakan materi yang dianggap paling sulit, 93,3\% siswa menginginkan adanya pengembangan media pembelajaran baru, 54\% siswa menginginkan multimedia interaktif. Kesimpulan dari penelitian ini adalah perlu dikembangkan media pembelajaran berupa multimedia interaktif berbasis Problem Based Learning pada materi "Sistem Imun" untuk kelas XI SMA.
\end{abstract}

\author{
Alamat Korespondensi: \\ Rinu Bhakti Dewantara \\ Pendidikan Biologi \\ Universitas Negeri Malang \\ Jalan Semarang 5 Malang \\ E-mail: tanyarinu@gmail.com
}

Indonesia menghadapi tantangan yang cukup besar dalam mempersiapkan masyarakatnya agar mampu bersaing di berbagai aspek kehidupan pada abad 21 ini. Badan Standar Nasional Pendidikan (2010) melaporkan bahwa negara-negara didunia saat ini berlomba-lomba dalam meningkatkan daya saing masyarakatnya melalui berbagai bidang terutama bidang pendidikan sehingga dapat menghadapi tantangan dan melihat peluang yang muncul dalam perubahan zaman yang terjadi secara global. Salah satu hal yang perlu dipersiapkan adalah aspek pendidikan, dalam pelaksanaanya pendidikan harus dapat memfasilitasi maupun mendorong siswa menjadi pebelajar yang mandiri, bertanggung jawab, kreatif, dan inovatif sehingga menghasilkan peserta didik yang memiliki keinginan kuat serta memiliki kemampuan belajar yang tinggi sehingga peserta didik dapat merespons tantangan dan menyesuaikan diri terhadap perubahan yang terjadi seiring perkembangan zaman (Kemendikbud, 2015). Persiapan tersebut dapat terealisasi dengan baik apabila ditunjang dengan terpenuhinya delapan standar nasional pendidikan, salah satunya adalah standar proses.

Standar proses pada pendidikan dasar dan menengah merupakan kriteria mengenai pelaksanaan pembelajaran pada satuan pendidikan dasar dan menengah yang digunakan untuk mencapai kompetensi lulusan (Kemendikbud, 2016). Selanjutnya, dinyatakan pula bahwa standar proses pada kurikulum 2006 belum menggambarkan urutan pembelajaran secara rinci sehingga menimbulkan penafsiran yang beragam dan berujung pada pembelajaran yang berpusat pada guru (teacher center) maka dikembangkan Kurikulum 2013 (K13). Konsep ideal standar proses kurikulum 2013 adalah berpusat pada siswa (student center), sifat pembelajaran yang konstekstual, buku teks yang memuat materi, proses pembelajaran yang efektif dan efisien, sistem penilaian yang komprehensif serta kompetensi yang diharapkan sesuai dengan kebutuhan.

Salah satu upaya untuk mencapai kompetensi pada K13 dalam implementasinya adalah melalui media pembelajaran interaktif. Penggunaan media pembelajaran daapt dipengaruhi oleh kemajuan teknologi, seperti media pembelajaran dengan bantuan komputer dan internet (Sessoms, 2008). Inovasi teknologi memberikan kemungkinan baru untuk perubahan proses belajar dan mengajar, progam pendidikan guru harus fokus pada pengembangan guru yang mempromosikan penerapan 
pembelajaran interaktif dan belajar dengan media digital, beberapa media digital dapat mendukung pembelajaran interaktif dan rencana belajar. Salah satu unsur penting dalam suatu proses pembelajaran adalah metode pembelajaran dan media pembelajaran karena dalam pemilihan suatu metode pembelajaran tertentu akan berpengaruh pada jenis media pembelajaran yang sesuai (Arsyad, 2013).

Multimedia interaktif adalah salah satu media pembelajaran berbasis komputer. Multimedia interaktif dapat menggabungkan semua media yang terdiri dari elemen teks, gambar, suara, animasi, dan video serta interaktivitas yang dikembangkan atas dasar teori dan prinsip-prinsip pembelajaran. Keunggulan multimedia interaktif di dalam interaktivitas adalah secara sifat mampu memaksa pengguna untuk berinteraksi dengan materi baik secara fisik dan mental yang dipengaruhi oleh keefektifan instruksi pada media sehingga mampu mendorong pengguna untuk aktif dalam pembelajaran yang disajikan. (Oka, 2017). Beberapa keunggulan lain ialah bahwa multimedia mampu mengubah pembelajar yang pasif menjadi pebelajar aktif, kemudian guru tidak lagi menjadi pusat informasi, melainkan menjadi fasilitator yang membimbing siswa dalam memperoleh pengetahuan (Vaughan, 2011). Terkait relevansi dengan Kurikulum 2013, multimedia yang dikembangkan oleh guru hendaknya ditunjang oleh model pembelajaran yang sesuai dengan pelaksanaan kurikulum 2013 yaitu menggunakan pendekatan saintifik; memfasilitasi siswa untuk melakukan learning by doing; penguasaan keterampilan abad 21 guna menghadapi berbagai tantangan abad ini. Salah satu model yang menerapkan pendekatan saintifik adalah model pembelajaran berbasis masalah (Problem based learning) (Kemendikbud, 2014). Masalah dapat diangkat dari hal-hal yang dapat dilihat oleh siswa dalam kehidupan sehari-hari.

Tujuan dari penelitian ini antara lain adalah sebagai berikut (1) menganalisis pembelajaran Biologi di kelas XI yang telah dilakukan; (2) menganalisis kebutuhan siswa terhadap multimedia interaktif; (3) menganalisis materi Biologi kelas XI yang dirasa sulit oleh siswa. Hasil analisis tersebut diharapkan mampu menjadi dasar bagi peneliti untuk merancang dan mengembangkan multimedia interaktif berbasis Problem Based Learning dan dapat digunakan sebagai rujukan bagi penelitian selanjutnya yang dilakukan oleh peneliti yang lain.

\section{METODE}

Jenis penelitian yang digunakan adalah penelitian deskriptif. Sampel yang dipilih dalam penelitian ini adalah 67 siswa kelas XII yang telah mempelajari materi pembelajaran Biologi kelas XI. Teknik pengambilan sampel dilakukan secara simple random sampling. Penelitian ini dilakukan pada bulan Agustus 2017. Teknik pengumpulan data yang digunakan berupa angket yang terdiri atas angket kebutuhan siswa. Data dianalisis secara deskriptif. Analisis kebutuhan ini merupakan tahap awal model pengembangan Lee, W.W. \& Owens (2004) yaitu analisis yang bertujuan untuk mengidentifikasi fakta yang ada dan menentukan kondisi ideal dengan mengembangkan produk yang sesuai dengan permasalahan.

\section{HASIL}

Analisis kebutuhan untuk siswa dilakukan dengan menggunakan angket yang terdiri atas beberapa aspek antara lain pengidentifikasian masalah dalam kegiatan pembelajaran Biologi di kelas XI, ketersediaan sumber belajar atau media pembelajaran, kepemilikan fasilitas pribadi penunjang pembelajaran, ketertarikan terhadap pengembangan sumber belajar atau media pembelajaran yang baru dan keterdukungan lingkungan sekolah dalam kegiatan belajar mengajar.

Pada aspek pengidentifikasian masalah dalam kegiatan pembelajaran, siswa diperkenankan untuk memilih lebih dari satu materi Biologi yang dianggap sulit untuk dipelajari pada saat kelas XI. Hasil yang diperoleh yaitu sebanyak $67,2 \%$ siswa memilih sistem imun, 38,8\% siswa memilih struktur dan fungsi jaringan hewan dan tumbuhan, 35\% siswa memilih sistem peredaran darah, 29,9\% siswa memilih sel, 23,9\% memilih sistem reproduksi, 22,4\% memilih sistem ekskresi, 19,4\% siswa memilih sistem gerak, $11,9 \%$ siswa memilih sistem pencernaan, dan 4,5\% siswa memilih sistem pernapasan.

Materi biologi yang dianggap sulit dipelajari oleh siswa disebabkan oleh beberapa hal. Hasil analisis angket menunjukkan fakta bahwa penyampaian guru kurang dapat dipahami oleh siswa, banyak istilah-istilah ilmiah yang sulit dimengerti, banyak bagian materi yang perlu dihafal, guru tidak memberikan klarifikasi dan penguatan di akhir presentasi yang dilakukan siswa, dan slide powerpoint yang digunakan guru untuk menyampaikan materi di depan kelas penuh dengan teks materi yang harus dibaca oleh siswa.

Metode yang sering digunakan guru selama pembelajaran cenderung monoton. Berdasarkan hasil angket, 97\% siswa menyatakan bahwa guru sering menerapkan metode presentasi kelompok. 45,6\% siswa menganggap guru sering menggunakan metode ceramah, $11,65 \%$ siswa mengungkapkan guru menerapkan metode diskusi, dan hanya 6,13\% siswa yang mengungkapkan bahwa guru menggunakan metode praktikum. Metode yang cenderung monoton dan kurang optimalnya pemanfaatan media pembelajaran berpengaruh kepada kesan dan tingkat pemahaman siswa terhadap materi yang telah dipelajari. 55\% siswa menganggap pembelajaran cenderung membosankan, 39\% siswa menganggap pembelajaran biasa saja dan hanya $6 \%$ siswa yang menganggap pembelajaran menyenangkan. Berkaitan tingkat pemahaman siswa, $65 \%$ siswa merasa bahwa memiliki pemahaman materi yang kurang, 28\% siswa merasa memiliki pemahaman materi yang cukup, dan hanya $7 \%$ siswa yang memiliki pemahaman materi yang baik. 
Pada aspek ketersediaan sumber belajar atau media pembelajaran, angket analisis kebutuhan memberikan informasi terkait sumber belajar yang sering digunakan siswa. Hasil angket menunjukkan bahwa sebanyak 74,62\% siswa masih bergantung pada buku paket, 34,33\% siswa menggunakan foto, 10,44\% siswa menggunakan powerpoint. Hasil angket juga menunjukkan bahwa 93,3\% siswa menginginkan adanya pengembangan sumber belajar yang baru dalam pembelajaran Biologi. Multimedia interaktif video animasi $(54,1 \%)$ menjadi sumber belajar terbanyak yang diinginkan oleh siswa, diikuti mobile learning $(31,6 \%)$, dan media realia (14,3\%). Pada aspek kepemilikan fasilitas pribadi penunjang pembelajaran, hasil angket mengungkapkan bahwa $100 \%$ siswa memiliki perangkat laptop atau komputer dan pada aspek keterdukungan lingkungan sekolah $100 \%$ mengungkapkan bahwa situasi di sekitar sekolah kondusif dan mendukung kegiatan pembelajaran di kelas dengan menggunakan multimedia. Adapun hasil analisis kebutuhan kepada siswa secara rinci ditampilkan pada tabel 1.

Tabel 1. Hasil Analisis Kebutuhan Multimedia Interaktif Berbasis Problem Based Learning untuk Siswa SMA Kelas XI

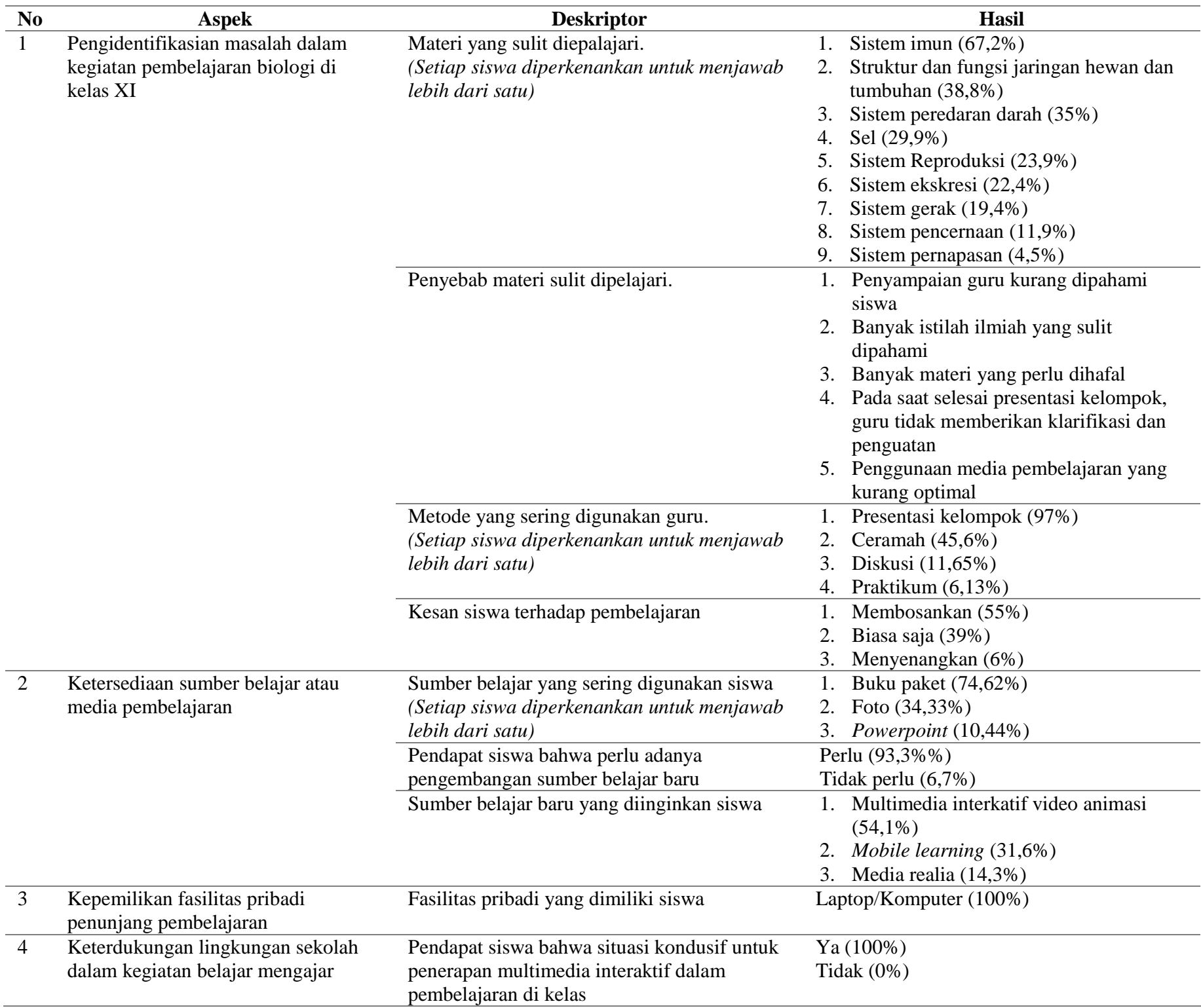

\section{PEMBAHASAN}

Pembelajaran adalah kegiatan yang dilakukan pendidik dalam merangsang, membimbing, mengarahkan dan mendorong serta mengorganisir proses belajar peserta didik sehingga memiliki pengetahuan dan mengembangkannya. Kualitas pembelajaran tercapai ketika hasil pembelajaran sesuai dengan tujuan yang direncanakan (Crosby, 1979). Kualitas pembelajaran selalu terkait dengan metode pengajaran, perilaku guru, keterlibatan siswa, media pembelajaran, materi pembelajaran, dan sistem pembelajaran (Depdiknas, 2004). Kualitas pembelajaran berkaitan dengan kinerja guru, pengetahuan guru, dan kreativitas guru (Blanton, Sindelar, \& Correa, 2006). 
Hasil penelitian yang diperoleh menunjukkan bahwa guru mata pelajaran Biologi kelas XI di SMAN 1 Way Jepara sudah berupaya untuk menerapkan berbagai macam metode pembelajaran, namun hanya didominasi oleh metode cermah dan metode presentasi. Metode mengajar dengan cara menyampaikan pengetahuan secara lisan menyebabkan siswa pasif dalam kegiatan pembelajaran sehingga cara tersebut bukan merupakan cara yang tepat dalam mengembangkan keterampilan abad 21 pada siswa (Syah, 2007). Pembelajaran yang hanya didominasi oleh metode tertentu saja membuat sebagian besar siswa merasa bosan. Metode pengajaran yang monoton tidak dapat memberikan tantangan kepada siswa untuk mempelajari materi sehingga siswa mudah merasa bosan dan juga berpengaruh pada penguasaan materi (Putri, 2013; Gilakjani, 2017) serta dapat membuat siswa kurang termotivasi untuk belajar (Andrini, 2016; Wahyunengsih, (2017). Fakta lain juga mengungkapkan bahwa guru juga jarang memberikan klarifikasi dan penguatan diakhir presentasi kelompok sehingga sebagian besar siswa merasakan memiliki pemahaman yang kurang terkait materi yang sudah dipelajari di kelas XI. Penguatan dalam pengajaran di kelas adalah hal yang tidak kalah penting karena dapat meningkatkan prestasi akademik dan membangun karakter siswa (Allred, 2008). Siswa yang mendapat penguatan dari guru dalam pembelajaran memperoleh rata-rata hasil belajar kognitif yang lebih tinggi dari pada siswa yang tidak mendapatkan penguatan (Hoque, 2013).

Sumber belajar yang sering digunakan sebagian besar siswa dalam mempelajari materi Biologi adalah buku paket. Kegiatan membaca memiliki efektivitas yang rendah dalam pemahaman materi yang bersifat abstrak, seperti pada materi-materi Biologi. Menurut Arsyad (2013) keterbatasan media cetak adalah sulit menampilkan gerak dalam halaman media cetakan, kemudian sangat jarang media cetak yang merancang sebuah teks yang menekankan emosi, perasaan, maupun sikap, dan apabila tidak diperlakukan dengan baik maka akan rusak atau hilang. Kustiawan (2016) menambahkan bahwa media cetak berupa buku teks terkadang menggunakan terminologi kata sehingga konsep yang di jelaskan menjadi sulit dipahami. Dale, (1969) menyatakan bahwa melalui aktivitas membaca, seseorang hanya memperoleh tingkatan sebesar $10 \%$ dalam hal mengingat dan memahami sesuatu yang ada di teks tersebut, sedangkan apabila seseorang hanya melihat sebuah gambar, maka hanya memperoleh tingkatan ingatan dan pemahaman sebesar 30\%. Berbeda halnya apabila media pembelajaran dikembangkan dengan desain yang baik, melibatkan video animasi, grafis, audio dan interaktivitas akan meningkatkan efektifitas penyerapan materi mencapai $80-90 \%$ (Wibawanto, 2017).

Materi Biologi kelas XI yang dianggap paling sulit bagi siswa, meliputi sistem imun, struktur fungsi jaringan hewan dan tumbuhan, dan sistem peredaran darah. Ketiga materi tersebut bersifat abstrak karena terdiri atas serangkaian mekanisme yang ada di dalam makhluk hidup sehingga diperlukan adanya media yang mampu memvisualisasikan secara konkret agar siswa memiliki pemahaman yang cukup mengenai materi tersebut. Materi yang dijadikan fokus dalam penelitian adalah materi yang mendapat respons paling sulit terbanyak yaitu Sistem Imun. Hal tersebut juga didukung oleh pencapaian hasil belajar kogntif siswa yang sangat rendah pada materi sistem imun dengan rata-rata nilai sebesar 38,13 . Angka tersebut berada jauh dari nilai standar kelulusan yang ditetapkan sehingga perlu diperbaiki. Kobe \& Tweed (2009) mengungkapkan alasan bahwa beberapa konsep dalam pembelajaran Biologi sulit dipelajari karena sangat konseptual dan siswa tidak dapat memvisualisasikan objek-objek yang berada pada level mikroskopis.

Materi Sistem Imun yang diberikan di kelas XI membahas mengenai peran sistem imun dan imunisasi terhadap fisiologi di dalam tubuh sesuai dengan KD 3.14. Proses pembelajaran materi Sistem Imun hendaknya menerapkan pendekatan kontekstual agar siswa mampu menghubungkan permasalahan yang terjadi dalam kehidupan sehari-hari dengan pengetahuan yang diperolehnya secara langsung agar pembelajaran menjadi bermakna. Sistem imun diperlukan oleh manusia agar tubuh tidak mudah terinfeksi oleh mikroorganisme penyebab infeksi. Menurut Dahar (2011) tiga manfaat belajar bermakna, meliputi informasi yang sudah dipelajari secara bermakna akan mudah diingat, informasi atau pemahaman baru yang dikaitkan dengan konsep relevan sebelumnya dapat meningkatkan konsep yang telah dikuasai, dan informasi yang pernah terlupakan setelah pernah dikuasai sebelumnya masih meninggalkan bekas sehingga dapat mempermudah proses belajar mengajar pada materi yang mirip walaupun telah lupa. Pembelajaran bermakna juga dapat berpengaruh pada hasil belajar siswa (Vallori, 2014; Fan \& Xiao, 2015). Model Problem Based Learning adalah model yang mengacu pada pendekatan kontekstual dan mampu memfasilitasi berkembangnya keterampilan abad 21 pada siswa. Problem Based Learning juga mendukung pola belajar bermakna (Sb, Ndlovu, \& Engelbrecht, 2014). Beberapa keunggulan Model Problem Based Learning adalah membantu siswa mentransfer pengetahuannya dalam memahami masalah dalam kehidupan sehari-hari, membantu siswa untuk mengembangkan pengetahuannya, bertanggung jawab dalam pembelajaran yang dilakukan, meningkatkan aktivitas belajar siswa, dan mampu mengembangkan keterampilan abad 21 (Hamruni, 2011).

Sistem pendidikan di seluruh dunia terus didorong untuk menggunakan teknologi dalam mengajarkan pengetahuan dan keterampilan yang dibutuhkan siswa pada abad ke-21 (Mahajan, 2012). Media pembelajaran yang dapat dikembangkan untuk memvisualisasikan materi yang bersifat abstrak dan mengembangkan keterampilan abad 21 adalah multimedia interaktif. Multimedia interaktif dapat meningkatkan motivasi peserta didik dan memudahkan siswa untuk belajar secara interaktif serta melatih siswa mandiri dalam memperoleh pengetahuan (Rajendra \& Sudana, 2018). Multimedia interaktif memiliki karakteristik bersifat konvergen sehingga dapat diintegrasikan dengan berbagai model pembelajaran, seperti Problem Based Learning. Multimedia interaktif yang akan dikembangkan berisi menu orientasi masalah, menu pembentukan kelompok, menu pengumpulan data, menu solusi, dan menu unggah karya, menu glosarium, dan menu game. Multimedia interaktif berbasis Problem Based Learning diaharapkan dapat menjadi solusi untuk mengatasi permasalahan yang ditemukan pada pembelajaran sistem imun di kelas XI. 


\section{SIMPULAN}

Metode yang diterapkan guru dalam pembelajaran Biologi belum memfasilitasi berkembangnya keterampilan abad 21 pada siswa secara maksimal. Penggunaan media pembelajaran sebagai prioritas sumber belajar pada proses pembelajaran Biologi yang bersifat abstrak belum dilakukan secara optimal. Materi sistem imun merupakan materi yang dianggap paling sulit oleh siswa sehingga dalam penyampaiannya dibutuhkan media yang dapat memvisualisasikan sistem imun secara konkret. Berdasarkan hasil analisis kebutuhan, maka disarankan untuk melakukan pengembangan multimedia interaktif berbasis Prolem Based Learning materi sistem imun kelas XI yang dapat mengembangkan keterampilan abad 21 dan hasil belajar kognitif pada siswa.

\section{DAFTAR RUJUKAN}

Allred, C. G. (2008). Seven Strategies for Building Positive Classrooms. Educational Leadership, 66(1).

Andrini, V. S. (2016). The Effectiveness of Inquiry Learning Method to Enhance. Journal of Education and Practice, 7(3), 3842.

Arsyad, A. (2013). Media Pembelajaran. Jakarta: PT Raja Grafindo Persada.

Blanton, L. P., Sindelar, P. T., \& Correa, V. I. (2006). Models and Measures of Beginning Teacher Quality. Journal of Special Education, 40(2), 115-127. https://doi.org/10.1177/00224669060400020201

Crosby, P. B. (1979). Quality is Free: Art of Making Quality Certain. New York.: McGraw Hill.

Dahar, R. W. (2011). Teori-Teori Belajar \& Pembelajaran. Jakarta: Erlangga.

Dale, E. (1969). Audio Visual Methods in Teaching. New York: Holt, Rinehart and Winston.

Depdiknas. (2004). Peningkatan Kualitas Pembelajaran. Jakarta: Depdiknas.

Fan, K., \& Xiao, P. (2015). The Effects of Learning Styles and Meaningful Learning on the Learning Achievement of Gamification Health Education Curriculum. Eurasia Journal of Mathematics, Science \& Technology Education, 11(5), 1211-1229. https://doi.org/10.12973/eurasia.2015.1413a

Gilakjani, A. P. (2017). Visual, Auditory, Kinaesthetic Learning Styles and Their Impacts on English Language Teaching. Journal of Studies in Education, 2(1), 104-113. https://doi.org/10.5296/jse.v2i1.1007

Hamruni. (2011). Strategi Pembelajaran. Yogyakarta: Insan Madani.

Hoque, S. R. (2013). "Effect of Reinforcement on Teaching - Learning Process." IOSR Journal of Humanities and Social Science, 7(1), 13-16. https://doi.org/10.9790/0837-0711316

Kemendikbud. (2012). Panduan Integrasi Pendidikan Karakter Pembelajaran IPA di Sekolah Dasar. Jakarta: Kementerian Pendidikan dan Kebudayaan.

Kemendikbud. (2015). Pelatihan Implementasi Kurikulum 2013. Jakarta: Kementerian Pendidikan dan Kebudayaan.

Kemendikbud. (2016). Permendikbud Nomor 22 Tahun 2016 Tentang Standar Proses Pendidikan dan Menengah. Jakarta: Kemendikbud.

Kobe, S., \& Tweed, A. (2009). Hard-to-Teach Biology Concepts: A Framework to Deepen Student Understanding. Virginia: NSTA Press.

Kustiawan, U. (2016). Pengembangan Media Pembelajaran Anak Usia Dini. Malang: Penerbit Gunung Samudera.

Lee. W.W. \& Owens. (2004). Multimedia-Based Instructional Design, (2nd Ed.). San Francisco: Pfeiffer.

Mahajan, G. (2012). Multimedia in Teacher Education: Perceptions \& Uses. Journal of Education and Practice, 3(1), 5-14.

Oka, G. P. A. (2017). Media dan Multimedia Pembelajaran. Yogyakarta: Deepublish.

Putri, D. S. A. (2013). The Use of Jigsaw II Technique and Still Pictures Combination to Improve Students' Vocabulary Mastery. Journal of English Language Teaching, 2(2), 1-11.

Rajendra, M, I., \& Sudana, M, I. (2018). The Influence of Interactive Multimedia Technology to Enhance Achievement Students on Practice Skills in Mechanical Technology. Journal of Physics: Conference Series, 953(012104), 1-5. https://doi.org/10.1088/1742-6596/953/1/012104

Sb, M., Ndlovu, M., \& Engelbrecht, P. (2014). Introducing Problem-Based Learning (PBL) into a Foundation Programme to Develop Self-Directed Learning Skills. Journal of Studies in Education, 34(1), 1-16. https://doi.org/10.15700/201412120928

Sessoms, D. (2008). Interactive Instruction : Creating Interactive Learning Environments Through Tomorrow's Teachers. International Journal of Technology in Teaching and Learning, 4(2), 86-96.

Vallori, A. B. (2014). Meaningful Learning in Practice. Journal of Education and Human Development, 3(4), 199-209. https://doi.org/10.15640/jehd.v3n4a18

Vaughan, T. (2011). Multimedia: Making It Work. 8th Edition. New York: McGraw-Hill.

Wahyunengsih. (2017). International Journal of English and Education Cooperative Integrative and Reading Composition Strategy to Enhance Reading Comprehension. International Journal of English and Education, 6(3), 285-299.

Wibawanto, W. (2017). Desain dan Pemrograman Multimedia Pembelajaran Interaktif. Jember: Cerdas Ulet Kreatif. 